\title{
openheart International guideline changes and the incidence of infective endocarditis: a systematic review
}

\author{
Omeair Khan, Ahmed Mohamed Abdel Shafi, Adam Timmis
}

To cite: Khan 0, Shafi AMA, Timmis A. International guideline changes and the incidence of infective endocarditis: a systematic review. Open Heart 2016;3: e000498. doi:10.1136/ openhrt-2016-000498

Received 12 July 2016 Revised 21 July 2016 Accepted 2 August 2016

Queen Mary University, London, UK

Correspondence to Professor Adam Timmis; adamtimmis@mac.com

\section{ABSTRACT}

The objective of this study was to determine the impact on incident infective endocarditis (IE) of guideline recommendations to restrict indications for antibiotic prophylaxis. We conducted a systematic review according to the Preferred Reporting Items for Systematic reviews and Meta-Analyses (PRISMA) guideline. PubMed and EMBASE databases were searched for articles published between 2007 and 2015 using mesh terms relevant to the research question. Included were English language articles published after 2009 that provided estimates of IE incidence before-and-after major international guideline changes. Seven studies were identified: 1 conducted in France, 4 in the USA and 2 in the UK. Only 1 study reported an increase in the rate of incident IE following guideline modification, and the remainder showed no change in upward (2 studies) or downward (4 studies) incidence trends. Study quality was generally poor for answering the question posed in this review, with serious risk of bias related to diagnostic ascertainment and unavailability of population risk data to adjust the incidence estimates. Moreover, the studies were often small, and relevant bacteriological data were not always available. Only 2 reported changes in antibiotic prescriptions, but these data were not linked to health records making it impossible to determine causal relations to changes in incident IE. The studies in this review were heterogenous in their design and variably limited by study size, duration of follow-up, diagnostic ascertainment, and absence of relevant prescription and bacteriological data. The studies were inconsistent in their conclusions and it remains uncertain what, if any, has been the impact of antibiotic prophylaxis guideline changes on the incidence of IE.

\section{INTRODUCTION}

Infective endocarditis (IE) is a relatively rare disorder with an estimated incidence of 3-10 cases per 100000 per year. ${ }^{1}$ Despite diagnostic and therapeutic advances, prognosis remains poor, as reflected by hospital mortality of about $22 \%$, rising to $40 \%$ at 5 years. ${ }^{2} 3$ Morbidity rates are also high; $50 \%$ of patients require operative management in the acute phase of the disease, often with ongoing consequences for quality of life. ${ }^{45}$ The substantial risk associated with IE has driven recommendations for antibiotic prophylaxis in high-risk subgroups, particularly those with valvular heart disease and other structural cardiac disorders.

Ever since the 1950s when the large-scale commercial production of penicillin was established, the American Heart Association (AHA) has advocated antibiotic prophylaxis in subgroups of patients undergoing invasive procedures, including dental extraction and certain gastrointestinal and genitourinary procedures, that are likely to cause secondary bacteraemia. ${ }^{6}$ Secondary bacteraemia in relation to these procedures is well documented but a causal relationship with IE has never been established in randomised trials or case-control studies. ${ }^{7} 8$ Despite this, antibiotic prophylaxis has remained a central component of management in at-risk individuals for over 50 years.

In 2002, innovative guidelines in France challenged accepted practice by suggesting restriction of prophylaxis against IE to patients with the highest ratio of benefit to individual and collective risk while emphasising the importance of general and oral hygiene in populations at risk. ${ }^{9}$ In 2007 , the AHA-followed in 2009 by the European Society of Cardiology (ESC)-withdrew recommendations for antibiotic prophylaxis in all but the highest risk individuals such as those with previous IE, prosthetic heart valves or immunodeficiency disorders. ${ }^{10}{ }^{11}$ The UK National Institute for Health and Care Excellence (NICE) made the yet more radical recommendation for complete cessation of antibiotic prophylaxis in all individuals regardless of risk. ${ }^{12}$ These new guideline recommendations, summarised in table 1, broke with a long-established principle of care and caused deep concern among many clinicians who cited historical, often small studies in questioning whether 
the recommendation was evidence based and whether it was safe for patients. ${ }^{13}$ NICE was unrepentant arguing that the absence of an evidence base was precisely why the need for antibiotic prophylaxis had been questioned and that the harms of anaphylaxis through wide-scale application of antibiotic prophylaxis were likely to exceed any potential benefits of IE prevention. ${ }^{14}$

The change in guidance has prompted studies internationally to analyse the impact on the incidence of IE. Findings have been inconsistent and there remains considerable uncertainty about the epidemiological consequences of the new guideline recommendations. In order to help resolve this uncertainty, we have undertaken a systematic review of studies to determine whether the change in guidance has been associated with an increase in the incidence of IE. Study characteristics of interest were defined as follows:

Population: healthy population cohorts;

Intervention: modified guideline recommendations for antibiotic prophylaxis against IE;

Comparisons: rate of incident IE before-and-after guide-

line modification;

Study design: observational cohort studies.

\section{METHODS}

The systematic review was conducted using Preferred Reporting Items for Systematic reviews and Meta-Analyses (PRISMA) guideline. ${ }^{15}$

\section{Eligibility criteria}

Studies were included based on a methodological approach taking into consideration the type of study, when the study was published, the study population and whether the study provided estimates of IE diagnostic rates before-and-after changes to guideline recommendations for antibiotic prophylaxis. Specific inclusion criteria were for studies with the following characteristics:

- Publication in the English language;

- Publication after the change in AHA antibiotic prophylaxis guidelines in 2007;

- Provision of estimates of IE incidence in the study population before the change of antibiotic prophylaxis guidelines and again for at least 1 year afterwards.

\section{Information sources and search strategy}

PubMed and EMBASE databases were searched for relevant articles published between 1 January 2007 and 1 December 2015. The search strategy, tailored to capture all variations in diagnostic, therapeutic and policy terminology, used mesh terms as follows: 'infective endocarditis', 'IE', 'endocarditis', 'infectious endocarditis', 'prophylaxis', 'prevention', 'antibiotics', 'guideline', 'recommendation' and 'policy'. Two independent reviewers applied the same database search methodology. Any discrepancies in search findings were resolved by consensus. All search results were downloaded to the EndNote Bibliography database manager where duplicates were excluded and the remaining studies were more carefully assessed prior to inclusion. There was no exclusion by population group. Primary exclusion was based on the title, abstract and key words. Potentially relevant articles were reviewed by both reviewers, and consensus about inclusion was reached. If the abstract was insufficient to formulate a final decision, the full text was reviewed to assess suitability for the purpose of this review.

\section{Selection and data collection process}

To avoid selection bias, reviewers independently conducted the search using the proposed search strategy. All relevant articles selected by the independent reviewers were then discussed by the reviewers before inclusion in the review. Each of the studies was then individually reviewed to summarise its findings in a table. After selection of the relevant studies, the data were extracted by one author into a table with predefined variables to summarise all the key points with respect to each of the included studies.

\section{Quality of the evidence}

Individual studies included in the review had a quality control assessment against modified STROBE checklist criteria for observational studies, particularly directed at assessing sources of bias. ${ }^{15}$

\section{Data synthesis}

No formal quantitative pooling of results was performed based on the heterogeneity of the studies in general and

\begin{tabular}{|c|c|c|c|c|}
\hline & $\begin{array}{l}\text { French recommendations } \\
2002\end{array}$ & $\begin{array}{l}\text { AHA } \\
2007\end{array}$ & $\begin{array}{l}\text { ESC } \\
2007\end{array}$ & $\begin{array}{l}\text { UK NICE } \\
2008\end{array}$ \\
\hline $\begin{array}{l}\text { Dental procedures involving manipulation of gingival } \\
\text { tissue in high-risk patients }\end{array}$ & Yes & Yes & Yes & No \\
\hline Prosthetic valve & Yes & Yes & Yes & No \\
\hline Previous IE & Yes & Yes & Yes & No \\
\hline Congenital heart disease & Yes & Yes & Yes & No \\
\hline Cardiac transplantation with valvular heart disease & Not specified & Yes & No & No \\
\hline Intermediate risk & Optional & No & No & No \\
\hline
\end{tabular}

AHA, American Heart Association; ESC, European Society of Cardiology; IE, infective endocarditis; NICE, National Institute for Health and Care Excellence. 
the data in particular. Synthesis of the data was performed qualitatively, and clinical implications are drawn.

\section{RESULTS}

\section{Study selection}

Of 2292 studies identified in the initial database search, 1305 were excluded after applying restrictions (figure 1). After reviewing the title, abstract and key words, a further 969 studies were excluded. The remaining 18 studies were subjected to full-text review which led to exclusion of another 11, either because IE incidence or trends in incidence were not reported or because the main focus of the articles was on prescription trends or clinicians' perspectives. The remaining seven studies ${ }^{16-22}$ fulfilled all inclusion criteria and are the subject of this review (table 1).

\section{Study characteristics}

The characteristics of the seven relevant studies are summarised in table 2 where each is allocated a study number. All were observational. Study 2 was conducted in France where the French guideline was implemented in 2002, and studies 3, 4, 6 and 7 were conducted in the USA where AHA guidelines were implemented in 2007. Study 1 was conducted in the UK where NICE guidelines were implemented in 2008 but, because follow-up was limited to 2 years, study 5 was later conducted providing an additional follow-up. In none of the studies were detailed descriptors of the denominator populations available. Studies $1,3,5$ and 7 were very large recruiting between 19804 and 457052 patients with IE but the remainder was smaller, study 6 from the USA recruiting just 27 patients. Study 2 from France compared rates of IE in discrete cohorts surveyed in 12-month periods before (1991 and 1999) and after (2008) the date of guideline change. The remaining six studies analysed trends in diagnostic rates across periods of 10-14 years that 'bridged' the dates of guideline implementation. Only studies 1 and 5 from the UK provided data on antibiotic prescriptions before-and-after guideline implementation. Data on bacteriological diagnosis were provided in all but one of the studies but, apart from study 6 , this was variably incomplete.

\section{Diagnostic ascertainment}

Study 2 collected cases of IE from participating clinicians with separate bacteriological confirmation and independent case validation by application of modified von Reyn and Duke criteria. Diagnostic ascertainment was also robust in study 6 which included patients with a definitive diagnosis of IE by Duke criteria. In all other studies, inclusion was based on the International Classification of Disease coding in the data source without further validation.

\section{Data sources}

Patients with IE were identified in national registries in UK studies 1 and 5 , in Medicare, voluntary or bespoke data collections in US studies 3, 4, 6 and 7 and in physician surveys in French study 2. In three studies, no age criteria were applied but in studies 2, 3, 4 and 6 , the study populations were selected by age: study 4 recruiting only patients aged $<18$, study 3 Medicare beneficiaries aged $>65$, and studies 2 and 6 adults aged $>20$ and $>18$, respectively.

\section{Study quality}

Selected quality indicators from the STROBE checklist relevant to the studies included in this review are shown

Figure 1 Selection of studies.

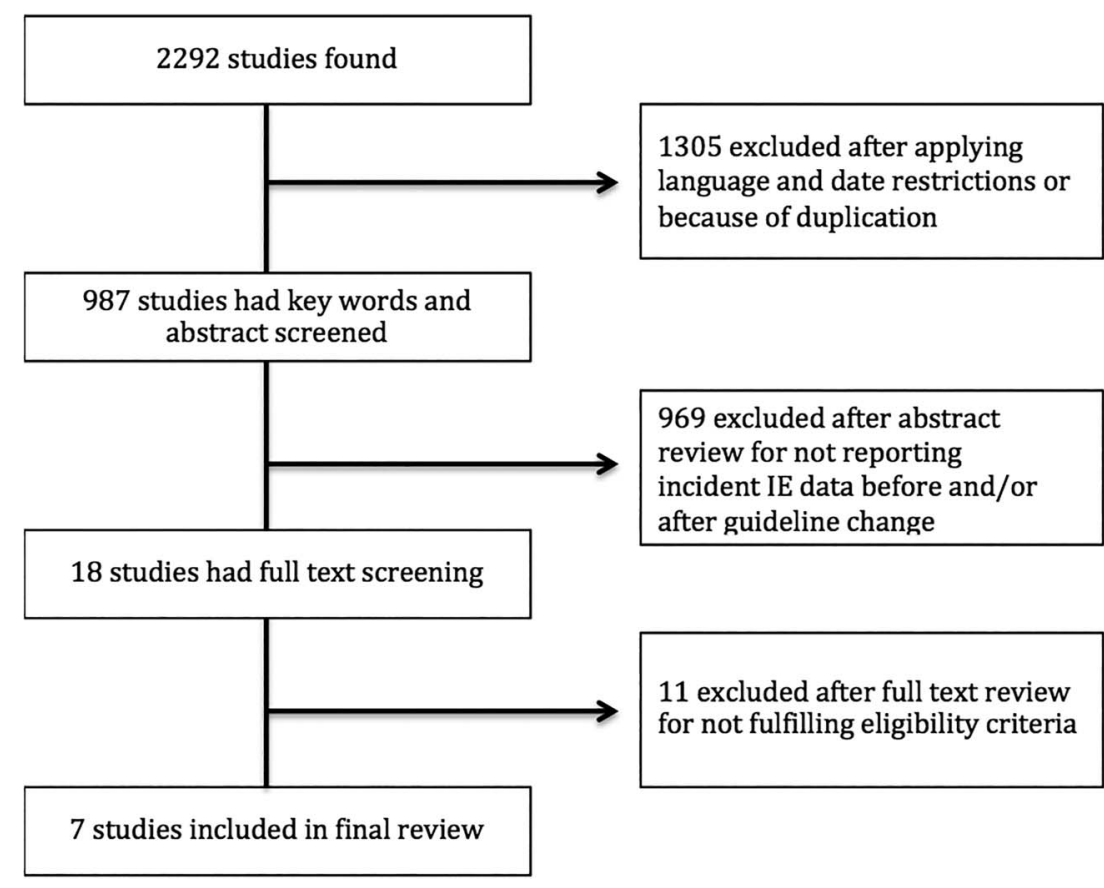




\begin{tabular}{|c|c|c|c|c|c|c|c|c|c|c|}
\hline Study & Country & Data source & Population & $\begin{array}{l}\text { Population } \\
\text { size }\end{array}$ & $\begin{array}{l}\text { Cases } \\
\text { of IE }\end{array}$ & Analysis & $\begin{array}{l}\text { Date of } \\
\text { guideline }\end{array}$ & IE incidence trends & $\begin{array}{l}\text { Change in IE } \\
\text { incidence after } \\
\text { guideline } \\
\text { change }\end{array}$ & $\begin{array}{l}\text { Prescription and } \\
\text { bacteriological } \\
\text { data }\end{array}$ \\
\hline $\begin{array}{l}\text { 6. DeSimone } \\
\text { et a } \text { F }^{1}\end{array}$ & $\begin{array}{l}\text { USA } \\
1999- \\
2013\end{array}$ & $\begin{array}{l}\text { Endocarditis } \\
\text { Registry at } \\
\text { Mayo Clinic } \\
\text { and } \\
\text { Rochester } \\
\text { Epidemiology } \\
\text { Project }\end{array}$ & $\begin{array}{l}\text { Olmsted } \\
\text { County adults } \\
\text { ( } \geq 18 \text { years) } \\
\text { with definite } \\
\text { or possible IE } \\
\text { caused by } \\
\text { streptococcal } \\
\text { viridans }\end{array}$ & NA & 27 & $\begin{array}{l}\text { Age-adjusted and } \\
\text { sex-adjusted } \\
\text { incidence rates } \\
\text { standardised } \\
\text { against the } 2010 \\
\text { US white } \\
\text { population }\end{array}$ & $\begin{array}{l}2007 \\
(\mathrm{AHA})\end{array}$ & $\begin{array}{l}\text { Incidence of IE } \\
\text { trended downward } \\
\text { during the study } \\
\text { period }\end{array}$ & $\begin{array}{l}\text { No change in } \\
\text { declining } \\
\text { trajectory }\end{array}$ & $\begin{array}{l}\text { Prescription data } \\
\text { unavailable } \\
\text { Only } 16 \% \text { of } \\
\text { cases caused by } \\
\text { streptococcus }\end{array}$ \\
\hline 7. Pant et a ${ }^{22}$ & $\begin{array}{l}\text { USA } \\
2000- \\
2011\end{array}$ & $\begin{array}{l}\text { The } \\
\text { Nationwide } \\
\text { Inpatient } \\
\text { Sample } \\
\text { database }\end{array}$ & $\begin{array}{l}\text { All patients } \\
\text { discharged } \\
\text { with acute } \\
\text { and subacute } \\
\text { bacterial } \\
\text { endocarditis }\end{array}$ & NA & 457052 & $\begin{array}{l}\text { Interrupted time } \\
\text { series analysis of } \\
\text { IE incidence rates }\end{array}$ & $\begin{array}{l}2007 \\
(\mathrm{AHA})\end{array}$ & $\begin{array}{l}\text { Steady increase in } \\
\text { the incidence of IE } \\
\text { hospitalisations from } \\
2000 \text { to } 2011\end{array}$ & $\begin{array}{l}\text { No significant } \\
\text { change in upward } \\
\text { trend }\end{array}$ & $\begin{array}{l}\text { Prescription data } \\
\text { unavailable } \\
\text { Increase in } \\
\text { streptococcal IE } \\
\text { cases after } 2007\end{array}$ \\
\hline
\end{tabular}

\begin{tabular}{|c|c|c|c|c|c|c|}
\hline & $\begin{array}{l}\text { Study population: } \\
\text { selection by age }\end{array}$ & $\begin{array}{l}\text { Monitoring period: } \\
\text { before/after guideline }\end{array}$ & $\begin{array}{l}\text { Diagnostic criteria } \\
\text { for IE }\end{array}$ & $\begin{array}{l}\text { Bacteriological data } \\
\text { reported }\end{array}$ & $\begin{array}{l}\text { Antibiotic data } \\
\text { reported }\end{array}$ & $\begin{array}{l}\text { IE rate estimate } \\
\text { adjustment }\end{array}$ \\
\hline $\begin{array}{l}\text { STROBE checklist } \\
\text { (paragraph number) }\end{array}$ & 6 & 5 & 7 & 7 & $14 a$ & $16 a$ \\
\hline 1. Thornhill et al ${ }^{16}$ & Unselected: all UK patients & $\begin{array}{l}8 / 2 \text { years, continuous } \\
\text { monitoring }\end{array}$ & ICD-10 codes & Yes, but incomplete & Yes & Unadjusted only \\
\hline 2. Duval et al ${ }^{17}$ & $\begin{array}{l}\text { Selected: adults } \geq 20 \text { years } \\
\text { from French region }\end{array}$ & $\begin{array}{l}\text { Isolated, cross-sectional } \\
\text { data collection } \\
11 / 3 \text { years }\end{array}$ & $\begin{array}{l}\text { Modified von Reyn } \\
\text { and Duke criteria }\end{array}$ & $\begin{array}{l}\text { Yes-high proportion } \\
\text { complete }\end{array}$ & No & $\begin{array}{l}\text { Adjusted for age and } \\
\text { sex only }\end{array}$ \\
\hline 3. Bikdeli et $a l^{18}$ & Selected: adults $\geq 65$ years & $8 / 3$ years & ICD-9 codes & No & No & $\begin{array}{l}\text { Adjusted for age, sex } \\
\text { and race }\end{array}$ \\
\hline 4. Pasquali et $a l^{19}$ & $\begin{array}{l}\text { Selected: children } \\
<18 \text { years }\end{array}$ & $7 / 3$ years & ICD-9 codes & $\begin{array}{l}\text { Yes-selected ICD-9 } \\
\text { codes }\end{array}$ & No & $\begin{array}{l}\text { Unadjusted incidence } \\
\text { only }\end{array}$ \\
\hline 5. Dayer et a ${ }^{20}$ & Unselected: all UK patients & $\begin{array}{l}8 / 5 \text { years continuous } \\
\text { monitoring }\end{array}$ & ICD-10 codes & Yes but incomplete & Yes & $\begin{array}{l}\text { Adjusted for size of } \\
\text { UK population only }\end{array}$ \\
\hline 6. DeSimone et $a^{R^{1}}$ & $\begin{array}{l}\text { Selected: adults } \geq 18 \text { years } \\
\text { in Olmsteasd County }\end{array}$ & $8 / 6$ years & Duke criteria & Yes-complete & No & $\begin{array}{l}\text { Adjusted for age and } \\
\text { sex only }\end{array}$ \\
\hline 7. Pant et $a^{2}$ & Unselected patients & $7 / 4$ years & ICD-9 codes & $\begin{array}{l}\text { Yes-selected ICD-9 } \\
\text { codes }\end{array}$ & No & $\begin{array}{l}\text { Unadjusted incidence } \\
\text { only }\end{array}$ \\
\hline
\end{tabular}


in table 3. The table documents the broad range of data sources for the seven studies, with variable age criteria for the study populations and uncertain diagnostic ascertainment of IE in all but studies 2 and 6. Antibiotic prophylaxis rates were captured in only two studies and although bacteriological data were presented in all but one, it was often incomplete with inclusion of streptococcal viridans isolation rates in only two of them. Incidence rates for IE were reported in all the studies but although some adjusted for age and sex, plus ethnicity in one, and the size of the denominator population in another, other potentially relevant confounders, particularly time-dependent changes in baseline risk characteristics of the denominator populations, were unavailable for modelling purposes introducing considerable bias into the incidence estimates.

\section{Study results}

\section{Infective endocarditis}

Only study 5 reported an increase in the rate of incident IE of 0.11 cases per 10 million per month $(p<0.0001)$ following guideline publication representing 35 more cases per month across the UK compared with the period before 2008. This change was associated with an $89 \%$ overall reduction in antibiotic prophylaxis prescriptions. A similar reduction in antibiotic prescription rates was reported in study 1 but there was no significant change in rates of IE which showed an upward trend throughout the study period. Study 7 also reported an upward trend in incident IE throughout the study period but no significant change with introduction of the 2007 AHA guideline. In studies 3 and 4, there was a declining trajectory of hospital admission with IE throughout the study periods with no change following introduction of the 2007 AHA guideline.

\section{Antibiotics and bacteriology}

Only studies 1 and 5 from the UK analysed prescriptions of a single $3 \mathrm{~g}$ dose of oral amoxicillin (or a $600 \mathrm{mg}$ dose of oral clindamycin for patients allergic to penicillin). In both studies, prescription data were obtained from the same national source and showed near identical $79 \%$ reductions following introduction of the 2008 NICE guideline. In study 1, discharge codes for streptococci were analysed, and notwithstanding the reduction in prophylactic antibiotic prescriptions, these showed no change in the upward trend of cases attributable to oral streptococcus although the authors acknowledged that the data were likely to be incomplete. Data on streptococcal isolates before-and-after guideline changes were also reported in three other studies, showing a decrease in studies 2 and 6 and no change in study 7 . In study 6 , the only one to report on streptococcal viridans isolates, rates did not change following the guideline change, and in study 5 , the bacteriological data were incomplete to the point that it did not provide the investigators with 'any meaningful information'.

\section{DISCUSSION}

This systematic review identified seven observational studies that have provided estimates of IE diagnostic rates before-and-after changes to national guideline recommendations. ${ }^{16-22}$ The quality of the studies was variable but generally insufficient to resolve uncertainty about how these changes have affected rates of incident IE; one of the studies reporting a small rate increase, whereas the others reporting no significant change compared to the period antedating guideline changes. It is unlikely that further observational studies of incident IE before-and-after guideline changes will be helpful in resolving this uncertainty.

Population studies of sufficient quality to provide confident estimates of how antibiotic prophylaxis affects rates of incident IE have proved hard to prosecute. The relative rarity of IE demands huge populations to generate sufficient cases. Only an estimated $35-45 \%$ of such cases, however, are due to oral streptococcal infection and of these only a proportion, perhaps half, are likely to result from invasive dental procedures making them potentially preventable by antibiotic prophylaxis. Add to this the increasing prevalence of staphylococcal endocarditis in recent years and it is clear that studies of almost unprecedented scale would be required to confidently identify changes in rates of incident IE in response to the antibiotic guideline changes. Whether any of the studies included in this review were sufficiently large enough to answer this question, therefore, is questionable. Numbers were large in four studies from the UK and USA, but the registry sources in these studies are potentially subject to under-reporting and coding inconsistencies either of which may have distorted incidence estimates and trends over time. ${ }^{23}$ The remaining studies were considerably smaller and although diagnostic ascertainment was a strength in two of them, the limited number of cases inevitably undermines confidence in the incidence analyses. In many of the studies, patient selection by age, hospital type or geographic area questions their generalisability, and in all of them, incidence estimates are undermined by the unavailability of risk factor data and other confounders. Thus, while incidence estimates were adjusted for age and sex in three studies plus ethnicity in one and the size of the denominator population in another, none was able to adjust for population risk factors such as structural cardiac disorders, implanted intravascular devices, diabetes and immunosuppression. This has major potential to distort the calculated IE incidence trends given the relative rarity of IE and the increasing numbers of people at risk in western populations through aortic valve disease, adult congenital heart disease and immunodepressive disorders. $^{24} 25$

In assessing the impact of guideline changes on incidence of IE, it should be recognised that the US and European guidelines ${ }^{10}{ }^{11}$ continued to advise antibiotic prophylaxis for very high-risk patients (prosthetic heart valves or prior endocarditis), unlike the UK's NICE 
guideline which was more radical in ruling out the need for antibiotic prophylaxis across all patient groups. ${ }^{12}$ It is instructive, therefore, to focus on the two studies from the UK because the impact of the 2008 guideline change was potentially greatest here. ${ }^{16}{ }^{20}$ Despite similarities between the studies in terms of their national perspective, patient identification and data analysis, only the more recent study by Dayer $e t a l,{ }^{20}$ with three additional years of follow-up, found a small but significant increase in the incidence of IE above the projected historical trend following the NICE guideline change. This was associated with a sharp 90\% reduction in antibiotic prescriptions. There is no clear explanation for the disparate findings of the two UK studies but the Dayer paper has been criticised for including 2007 data in the postguideline analysis even though the guideline was not introduced until October that year. ${ }^{26}$ Moreover, a recent critique of the Dayer study in the NICE clinical guideline update concluded that the study, in particular the change in slope of the IE incidence curve, was at high risk of bias. ${ }^{27}$ Certainly, as the editorialist emphasised, ${ }^{28}$ the temporal association between reduced antibiotic prescriptions and increased rates of IE reported by Dayer et $a l^{20}$ do not prove causality, not least because there was no adjustment for temporal changes in major risk factors for IE, including age, in the annual incidence calculations.

Although the studies included in this review sought to determine how guideline-recommended changes in antibiotic prophylaxis have affected incident IE, only the two UK studies reported prescription data. Without prescription data, it is simply not possible to determine whether temporal changes in incident IE have been influenced by changes in antibiotic prophylaxis called for in guidelines. For the two UK studies, it must be recognised that prescription data were not linked to the health records which, coupled with the unadjusted incidence calculations, makes it impossible to determine whether the sharp reduction in prescriptions following the 2009 NICE guideline was causally related to changes in incident IE. The monitored prescriptions for a single $3 \mathrm{~g}$ dose of oral amoxicillin (or a $600 \mathrm{mg}$ dose of oral clindamycin for patients allergic to penicillin) account for the large bulk of prophylactic treatment in patients undergoing dental work and are targeted against streptococcal infection. Logically, therefore, any change consequent to the guideline recommendations should be confined largely to streptococcal IE. It was a limitation of the Dayer study ${ }^{20}$ that the infective organism was not available to the investigators and we do not know, therefore, if the small increase in the recorded incidence of IE after 2008 was driven by increases in streptococcal IE. The earlier UK study, however, found no apparent change in the upward trend of streptococcal IE after 2008, although the recording of infective organisms was incomplete and captured streptococcal infection generically without specification of the viridans species. ${ }^{16}$ Nevertheless, the French study, the smaller
Olmstead County study and the US Children's study $^{17} 1921$ also reported no increases in cases of streptococcal infection after the guideline changes. Only the large US study by Pant $e t a l^{22}$ reported an increase in streptococcal IE hospitalisation rates although overall trends in IE hospitalisations from 2000 to 2007 and from 2008 to 2011 were not significantly different.

The sharp fall in UK prophylactic antibiotic prescriptions in 2008 reflects a level of adherence to the guideline changes. This is consistent with the results of a survey in which $87 \%$ of UK dentists reported adherence to the NICE guidance, although $35 \%$ admitted administering antibiotic prophylaxis after the guideline change. Among cardiologists and cardiothoracic surgeons, only $61 \%$ reported adherence. ${ }^{29}$ A more contemporary US survey of paediatric cardiologists found that more than half of the participants $(56 \%)$ do not follow current antibiotic prophylaxis guidelines. ${ }^{30}$ This variable, often low level of adherence, further limits the ability of the studies included in this review to provide reliable estimates of the impact of guideline changes on the incidence of IE.

Since this systematic review was completed, at least two further studies have been published aimed at determining the impact of antibiotic prophylaxis guideline changes on the incidence of IE. ${ }^{31}{ }^{32}$ Similar limitations to those discussed in this review applied to both studies, one of which reported no impact of the guideline ${ }^{31}$ and the other a negative impact reflected in a significant increase in streptococci-related IE cases. ${ }^{32}$

Concerns that international guideline changes to recommendations for antibiotic prophylaxis in at-risk patients might lead to an increase in rates of IE have not been resolved by the observational studies included in this systematic review. The heterogeneity of the studies makes robust conclusions impossible particularly given their variable methodological limitations, including study size, duration of follow-up, diagnostic ascertainment, uncertainty about guideline adherence, and absence of relevant prescription and bacteriological data. Many of the studies suggested an upward trend in incident IE not obviously associated with the guideline changes and there is a clear need for onward monitoring. However, further before-and-after observational studies of the type included in this review will not be helpful in determining the impact of the antibiotic prophylaxis guideline changes without detailed clinical phenotyping of unselected registry populations at scale, with linked prescribing and bacteriological data.

Contributors OK contributed to project planning, literature searches, data interpretation and writing of the manuscript. AMAS contributed to literature searches and manuscript review. AT contributed to project planning, data interpretation and writing of the manuscript.

Funding AT acknowledges support of Barts and the London Cardiovascular Biomedical Research Unit, funded by the National Institute for Health Research.

Competing interests None declared.

Provenance and peer review Not commissioned; externally peer reviewed. 
Data sharing statement No additional are available.

Open Access This is an Open Access article distributed in accordance with the Creative Commons Attribution Non Commercial (CC BY-NC 4.0) license, which permits others to distribute, remix, adapt, build upon this work noncommercially, and license their derivative works on different terms, provided the original work is properly cited and the use is non-commercial. See: http:// creativecommons.org/licenses/by-nc/4.0/

\section{REFERENCES}

1. Prendergast $\mathrm{BD}$. The changing face of infective endocarditis. Heart 2006;9:879-85.

2. Diz Dios P. Infective endocarditis prophylaxis. Oral Dis 2014;20:325-8.

3. Selton-Suty C, Celard M, Le Moing V, et al. Preeminence of Staphylococcus aureus in infective endocarditis: a 1-year population-based survey. Clin Infect Dis 2012;54:1230-9.

4. Moreillon P, Que YA. Infective endocarditis. Lancet 2004;363:139-49.

5. Verhagen DW, Hermanides J, Korevaar JC, et al. Health-related quality of life and posttraumatic stress disorder among survivors of left-sided native valve endocarditis. Clin Infect Dis 2009;48:1559-65.

6. Lockhart PB, Loven B, Brennan MT, et al. The evidence base for the efficacy of antibiotic prophylaxis in dental practice. J Am Dent Assoc 2007;138:458-74

7. Strom BL, Abrutyn E, Berlin JA, et al. Dental and cardiac risk factors for infective endocarditis. A population-based, case-control study. Ann Intern Med 1998;129:761-9.

8. Van der Meer JT, Van Wijk W, Thompson J, et al. Efficacy of antibiotic prophylaxis for prevention of native-valve endocarditis. Lancet 1992;339:135-9.

9. Danchin N, Duval X, Leport C. Prophylaxis of infective endocarditis: French recommendations 2002. Heart 2005;91:715-18.

10. Wilson W, Taubert KA, Gewitz M, et al. Prevention of infective endocarditis: guidelines from the American Heart Association: a guideline from the American Heart Association Rheumatic Fever, Endocarditis and Kawasaki Disease Committee, Council on Cardiovascular Disease in the Young, and the Council on Clinical Cardiology, Council on Cardiovascular Surgery and Anesthesia, and the Quality of Care and Outcomes Research Interdisciplinary Working Group. J Am Dent Assoc 2007;138:739-45, 47-60.

11. Habib G, Hoen B, Tornos $\mathrm{P}$, et al. Guidelines on the prevention, diagnosis, and treatment of infective endocarditis (new version 2009): the Task Force on the Prevention, Diagnosis, and Treatment of Infective Endocarditis of the European Society of Cardiology (ESC). Endorsed by the European Society of Clinical Microbiology and Infectious Diseases (ESCMID) and the International Society of Chemotherapy (ISC) for Infection and Cancer. Eur Heart $J$ 2009;30:2369-413.

12. Prophylaxis against infective endocarditis: antimicrobial prophylaxis against infective endocarditis in adults and children undergoing interventional procedures. NICE guidelines [CG64] Published date: March 2008. https://www.nice.org.uk/guidance/cg64/

13. van der Meer JT, Thompson J, Valkenburg HA, et al. Epidemiology of bacterial endocarditis in the Netherlands. II. Antecedent procedures and use of prophylaxis. Arch Intern Med 1992;152:1869-73.
14. Chambers J, Shanson D, Hall R, et al. Antibiotic prophylaxis of endocarditis: the rest of the world and NICE. J Roy Soc Med 2011;104:138-40.

15. The Strengthening the Reporting of Observational Studies in Epidemiology (STROBE) Statement: guidelines for reporting observational studies. http://www.equator-network.org/ reporting-guidelines/strobe/

16. Thornhill MH, Dayer MJ, Forde JM, et al. Impact of the NICE guideline recommending cessation of antibiotic prophylaxis for prevention of infective endocarditis: before and after study. BMJ 2011;342:d2392.

17. Duval X, Delahaye F, Alla F, et al. EPEI Study Group. Temporal trends in infective endocarditis in the context of prophylaxis guideline modifications: three successive population-based surveys. J Am Coll Cardiol 2012;59:1968-76.

18. Bikdeli B, Wang Y, Kim N, et al. Trends in hospitalization rates and outcomes of endocarditis among Medicare beneficiaries. J Am Coll Cardiol 2013:62:2217-26.

19. Pasquali SK, He X, Mohamad Z, et al. Trends in endocarditis hospitalizations at US children's hospitals: impact of the 2007 American Heart Association Antibiotic Prophylaxis Guidelines. Am Heart J 2012;163:894-9.

20. Dayer MJ, Jones S, Prendergast B, et al. Incidence of infective endocarditis in England, 2000-13: a secular trend, interrupted time-series analysis. Lancet 2015;385:1219-28.

21. DeSimone DC, Tleyjeh IM, Correa de Sa DD, et al. Temporal trends in infective endocarditis epidemiology from 2007 to 2013 in Olmsted County, MN. Am Heart J 2015;170:830-6.

22. Pant S, Patel NJ, Deshmukh A, et al. Trends in infective endocarditis incidence, microbiology, and valve replacement in the United States from 2000 to 2011. J Am Coll Cardiol 2015;65:2070-6.

23. Denaxas SC, Morley KI. Big biomedical data and cardiovascular disease research: opportunities and challenges. Eur Heart J Qual Care Clin Outcomes 2015;1:9-16.

24. Warnes CA, Liberthson R, Danielson GK, et al. Task force 1: the changing profile of congenital heart disease in adult life. J Am Coll Cardiol 2001;5:1170-5.

25. d'Arcy JL, Prendergast BD, Chambers JB, et al. Valvular heart disease: the next cardiac epidemic. Heart 2011;97:91-3.

26. Kazi DS, Bolger AF. MD caveat emptor antibiotics, endocarditis, and statistical artifacts. J Am Coll Cardiol 2016;67:2088-90.

27. NICE guideline CG64 update 2015. https://www.nice.org.uk/ guidance/cg64/evidence/full-guideline-addendum-196759982

28. Duval X, Hoen B. Prophylaxis for infective endocarditis: let's end the debate. Lancet 2015;385:1164-5.

29. Dayer MJ, Chambers JB, Prendergast B, et al. NICE guidance on antibiotic prophylaxis to prevent infective endocarditis: a survey of clinicians' attitudes. QJM 2013;106:237-43.

30. Naik RJ, Patel NR, Wang M, et al. Infective endocarditis prophylaxis: current practice trend among paediatric cardiologists: are we following the 2007 guidelines? Cardiol Young 2016;26:1176-82.

31. Mackie AS, Liu W, Savu A et al. Infective endocarditis hospitalizations before and after the 2007 American Heart Association prophylaxis guidelines. Can J Cardiol 2016;32:942-8.

32. van den Brink FS, Swaans MJ, Hoogendijk MG, et al. Increased incidence of infective endocarditis after the 2009 European Society of Cardiology Guideline Update: a nation-wide study in the Netherlands. Eur Heart J Qual Care Clin Outcomes 2016. In press. 